\title{
Adolescent pregnancy in Zambia
}

Population Council

Follow this and additional works at: https://knowledgecommons.popcouncil.org/departments_sbsr-rh

Part of the Demography, Population, and Ecology Commons, Family, Life Course, and Society Commons, and the International Public Health Commons How does access to this work benefit you? Let us know!

\section{Recommended Citation}

"Adolescent pregnancy in Zambia," Policy brief. Lusaka: Population Council, 2017. 


\section{ADOLESCENT PREGNANCY IN ZAMBIA}

Adolescent pregnancy undermines girls' human rights and compromises their opportunity to fully realize their socioeconomic development potential. Adolescent girls have the right to education, health, dignity, nondiscrimination, and quality of life.

Protecting, promoting, and fulfilling these rights is necessary to ensure that girls grow into healthy, skilled, productive, independent, and responsible adults, and yet the prevalence of adolescent pregnancy stands in the way of ensuring these rights. Most adolescent girls drop out of school when they are pregnant, which compromises their future because they grow up with limited career options and opportunities. Furthermore, some girls will have unsafe abortions that lead to injuries, disability, and sometimes death. Engaging in unprotected sex also puts adolescent girls at higher risk of contracting STIs, including HIV-all adverse consequences.

Adolescence is a period of preparation for adulthood during which several key development experiences occur. Besides physical and sexual maturation, these experiences include development toward social and economic independence, development of identity, acquisition of skills needed to carry out adult relationships and roles, and development of abstract reasoning. Adolescents should therefore be supported to navigate safely through this crucial stage in the life course.

\section{Prevalence of Adolescent Pregnancy} In 2015, the Population Council in conjunction with UNFPA conducted a study that drew on data from the 2013-14 Zambia Demographic and Health Survey (ZDHS) and the 2010 Census of Population and Housing to identify where adolescent pregnancy is

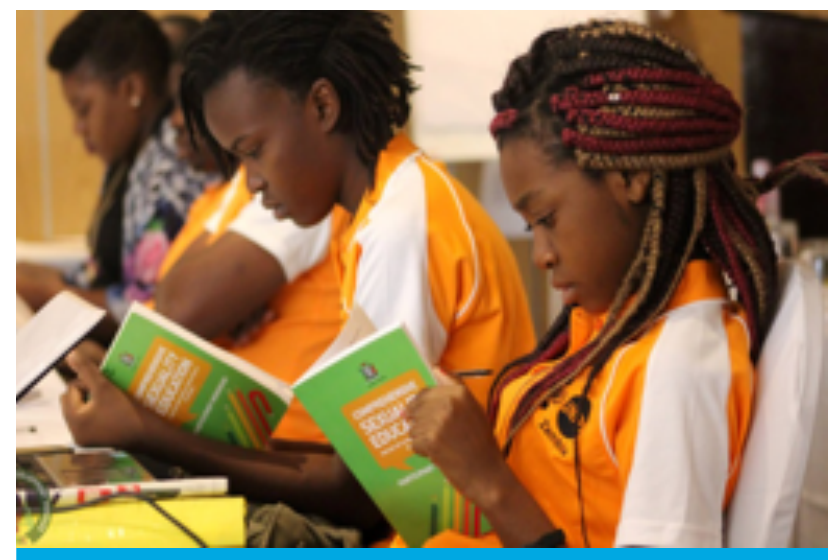

Effects of Adolescent Pregnancy

- Reduces girls' opportunities for education, because pregnant girls drop out of school earlier than boys, fewer return to continue their education, and lack of education perpetuates poverty among girls, women, and their families and communities.

- Causes psychological stress in adolescents. This may lead to unsafe abortion, which can result in severe pregnancy complications and maternal death.

- Exposes adolescent girls to sexually transmitted infections, including HIV, and to the human papillomavirus (HPV), which is responsible for causing cervical cancer.

- Children born to adolescent mothers may experience a wide range of problems, for example they are at greater risk of low birth-weight, stunting, and infant mortality. Poor health associated with being born to adolescent mothers may also prevent children from being active in school and from completing their education. 
most likely to occur in Zambia. Using a literature review, key informant interviews among organizations working with adolescents, and in-depth interviews with adolescent girls, the study also identified key factors that lead to adolescent pregnancy.

Study findings reaffirmed that adolescent pregnancies are high in Zambia (see Figure 1). According to the 201314 ZDHS, $28.5 \%$ of girls aged $15-19$ have ever been pregnant or had a live birth. There are regional differences in adolescent pregnancy. The Copperbelt has the lowest proportion of girls aged 15-19 ever pregnant (16-19\%), while the Western Province (38-41\%) and the North Western Province (41\%) have the highest proportions (CSO, $\mathrm{MOH}$, and ICF International 2014). The rates of adolescent pregnancy are higher in rural areas, where 37\% report ever being pregnant or having a live birth compared with $20 \%$ in urban areas. When analysed by province, there are significant differences between urban and rural areas in each province. The highest rates are in rural communities of Northwestern and Western Provinces where the proportion of ever-pregnant females was $44 \%$ and $43 \%$, respectively, while in urban areas in these provinces it was 34\%. Adolescents in the lowest wealth quintiles are more likely to become pregnant than those in the highest quintiles. Almost half of girls aged 15-19 (45\%) in the lowest wealth quintile have ever been pregnant compared with $10 \%$ in the highest wealth quintile. This suggests that being poor and living in rural areas predisposes adolescents to early pregnancy.

The study also analysed reports by the Ministry of Education on adolescent pregnancies in schools. Between 2007 and 2014 , a total of 120,024 in-school girls became pregnant and dropped out. The majority of the girls, 103,621, were in primary school when they became pregnant as compared with 16,403 who were in secondary school (Ministry of Education, Science, Vocational Training, and Early Education 2015). Girls between grades 5 and 9 are most susceptible to adolescent pregnancy.

\section{Potential Hotspots for Adolescent Pregnancy}

Data analysis at the district level showed that districts in Western and North Western Provinces are hotspots for teenage pregnancy. Girls living in these parts of the country are more likely to become pregnant as teenagers than girls living elsewhere. Shangombo and Sesheke in Western province and Chama in Muchinga Province have the highest likelihood of adolescent pregnancy. In Shangombo, the predicted probability is 0.52 meaning that more than half of all girls aged 15-19 are predicted to experience a pregnancy. Figure 2 shows areas of high predicted probability of pregnancy in red/dark-orange colors, and areas of low predicted pregnancy in blue colors. The lowest predicted probabilities for pregnancy are in Chingola, Kitwe, and Luanshya districts in the Copperbelt Province and Kabwe in Central Province. Additional studies will be required to understand what is protective in these districts of low predicted probability of pregnancy and the driving factors in the districts with high pregnancy rates.

\section{Determinants of Adolescent Pregnancy}

Factors associated with adolescent pregnancy are complex and often intertwined and driven by various social, economic, and sexual-relations patterns that are further influenced by other underlying issues such as age, peer-group experiences, gender dynamics, and vulnerabilities created by various circumstances in which adolescents find themselves. Overall determinants of adolescent pregnancy from the study were classified into five categories: (1) lack of access to appropriate sexual and 
reproductive health information and services, particularly contraceptives; (2) poverty, which leads some girls to offer sex in exchange for money, goods, and services; (3) social and cultural determinants, such as gender inequality (women and girls perceived as the weaker sex), child marriage, and peer pressure; (4) lack of information and education on sex and sexuality; and (5) lack of opportunities for adolescents, particularly for those living in rural areas, such as school boarding facilities and social services (long distances to schools, health facilities, and entertainment).

\section{Recommendations}

Keep girls in school

Starting in Grade 6, significantly more girls drop out of school in Zambia than boys. In 2014, of the children in grades 1 through $7,2.1 \%$ of girls dropped out of school as compared to $1.5 \%$ of boys. Similarly, for those in grades 8 through $12,1.8 \%$ of girls dropped out of school as compared with $0.6 \%$ of boys (Ministry of Education, Science, Vocational Training, and Early Education 2015). Fewer girls get pregnant in secondary school than in primary school, which suggests that the longer they stay in school the less likely it is for them to get pregnant. International evidence also suggests that keeping girls in school and enabling them to have an education has a positive effect on their personal lives and has potential for positive impact on future generations (World Bank 2015). To keep girls in school, there is a need to:

- Prevent child marriage.

- Ensure that both infrastructure and human resources are available for girls to attend school.

- Ensure that the school environment is configured to meet the needs of adolescents, including having proper sanitary facilities, and eliminating bullying, especially by boys and male teachers.
Provide sexual and reproductive health information The African Charter on the Welfare and Rights of the Child, in Article 4, states that "in all actions concerning the child undertaken by any person or authority, the best interests of the child shall be the primary consideration." Government has an obligation to systematically consider adolescents' evolving capacities and ensure that appropriate information and services are made available independent of parental or guardian authorization when this is in the best interest of the adolescent. Age-appropriate SRH information should target young adolescents and start as early as possible in a person's life. Government and its stakeholders should:

- Educate adolescents on human rights and gender equality.

- Empower adolescents with knowledge and information on condoms as dual protection against pregnancy and STIs, and on contraceptives to prevent pregnancy.

- Remove restrictions on parental consent to access HIV and reproductive health services and train health care workers not to stigmatize adolescents who seek reproductive health services in health facilities. 
Strengthen referrals between school and health facilities Although government has introduced Comprehensive Sexuality Education (CSE) in schools, there are limited adolescent-friendly health services and referrals between schools and health facilities for reproductive health services. In addition, adolescents have limited information on where and how to access SRH services. There is therefore a need to ensure that the Ministry of Health, the Ministry of Education, and the Ministry of Youth and Sport develop adequate referral systems that link adolescents to sexual and reproductive health services within the health systems. For example, the Ministry of Health can develop comprehensive health outreach services (health fairs) within school and youth centers on a regular basis where they provide SRH services along with other general health services such as diabetes testing and hypertension screening. Another way to increase access to services is to ensure that within the vicinity of every school there is a health facility providing adolescent responsive and friendly services.

Provide out-of-school girls with health, economic, and educational opportunities

In Zambia, many adolescent girls do not complete primary school because of pregnancy, economic factors, or a number of other reasons. This group of girls faces various development challenges including limited socioeconomic opportunities. It is recommended that to prevent teenage pregnancy and ensure quality of life, the government, the private sector, civil society, and faith communities should strengthen school reentry implementation and community sensitization to allow girls who have dropped out of school to return, while providing out-of-school girls with the skills required to increase their chances of being employed or starting their own businesses as well as life skills to support their transition to responsible adulthood. Government should also direct the social cash transfer program implemented by the Ministry of Community Development and Social Services to vulnerable households where there are adolescent girls, to mitigate the poverty situation that increases the vulnerability of adolescent girls to pregnancy.

Eliminate child marriage and support married young girls Although the age of marriage according to the Marriage Act in Zambia is 21 years, customary law allows adolescent girls to marry at a young age as long as they have reached puberty. As a result, child marriage is high in Zambia, estimated at $31.4 \%$ for girls aged $20-24$, and it affects more girls (17\%) than boys (1\%) (CSO, MOH, and ICF International 2014). Child marriage leads to adolescent pregnancy with negative health and development consequences.

Government should, among other things, enact laws prohibiting child marriage, engage traditional leaders to eliminate negative cultural practices, provide economic empowerment to families and adolescents to protect them from child marriage, and conduct sustained public media campaigns against child marriage.

\section{References}

Central Statistical Office (CSO), Ministry of Health (MOH), and ICF International. 2014. Zambia Demographic and Health Survey 2013-14. Rockville, Maryland, USA.

Ministry of Education, Science, Vocational Training and Early Education. 2015. "Educational Statistical Bulletin Tables." Lusaka, Zambia: Directorate of Planning and Information.

World Bank. 2015. “Adolescent Girls in Zambia.” Policy Brief: Zambia. https://openknowledge.worldbank. org/bitstream/handle/10986/24576/k8898. pdf?sequence=2\&isAllowed=y. Accessed 5 May 2016.

Suggested citation: Population Council, UNFPA, and Government of the Republic of Zambia. 2017. "Adolescent Pregnancy in Zambia." Lusaka, Zambia.

Photo credit: United Nations Population Fund (UNFPA).

\section{The United Nations Population Fund (UNFPA)}

Delivering a world where every pregnancy is wanted, every childbirth is safe and every young person's potential is fulfilled. unfpa.org

The Population Council conducts research and delivers solutions that improve lives around the world. Big ideas supported by evidence: It's our model for global change. popcouncil.org 